\title{
Prevalence of Clinically Diagnosed Acute Otitis Media (AOM) in the Philippines: a National Survey with a Developing Country's Perspective
}

\author{
Ruzanne M. Caro, ${ }^{1}$ Erasmo Gonzalo DV. Llanes, ${ }^{1}$ Rosario R. Ricalde ${ }^{1}$ and Jesus N. Sarol Jr. ${ }^{2}$ \\ ${ }^{1}$ Department of Otorhinolaryngology, College of Medicine and Philippine General Hospital, University of the Philippines Manila \\ ${ }^{2}$ National Teacher Training Center for the Health Professions, University of the Philippines Manila
}

\begin{abstract}
Background and Aims. Acute otitis media (AOM) seems to be a significant public health problem, but national data on its prevalence is lacking. This study aims to determine the prevalence of acute otitis media in the Philippines and characterize this population.

Methods. A cross-sectional survey of children 0-12 years old in community health centers and schools was performed, utilizing a multi-stage cluster sampling design.
\end{abstract}

Results. Thirteen areas were included in the survey with 26 household and school clusters, surveying a total of 2,277 children. There were 218 children with clinically diagnosed acute otitis media, with an overall prevalence rate of $9.6 \%$. Among the children with AOM, 108 (10\%) were male while 110 (9.2\%) were female. There were $32(14.6 \%)$ cases of AOM in the $0-2$ year olds, $56(9.5 \%)$ in the 3-6 year olds, and $117(8.4 \%)$ in the $7-12$ year old children.

Conclusions. The overall prevalence of clinically diagnosed acute otitis media in the Philippines is $9.6 \%$, with a variable areaspecific prevalence. There is no gender predilection, with the $0-2$ age group having the most prevalent cases of AOM in the sample.

Key Words: acute otitis media, otitis media, middle ear inflammation

\section{Introduction}

With the advent of preventive strategies to control pneumococcal antibiotic-resistant acute otitis media (AOM), many countries are currently reviewing their burden of disease data to assess the cost-effectiveness of such interventions. ${ }^{1,2,3}$ Among developed and developing countries, acute otitis media is a major public health problem, affecting young children and other vulnerable subsets of the population, and as a precursor of chronic

Paper was presented as a poster at the 7th World Society for Pediatric Infectious Diseases Congress, Nov 16-19, 2011, Melbourne, Australia.

Corresponding author: Ruzanne M. Caro, MD

Department of Otorhinolaryngology

Philippine General Hospital

University of the Philippines Manila

Taft Avenue, Ermita, Manila 1000 Philippines

Telephone: +6325548467

Email: ruzannecaro@yahoo.com suppurative otitis media, which causes life-threatening complications and is a major preventable cause of hearing impairment. Recurrent acute otitis media alone can cause significant morbidity among children resulting to school absences and reduced quality of life. ${ }^{2}$ Prevalence data on acute otitis media is difficult to obtain in developing countries such as the Philippines due to the massive human and logistic resources needed to collect data as a populationbased study.

Acute otitis media is a disease resulting from a bacterial infection, more commonly by Streptococcus pneumoniae, Haemophilus influenza, and Moraxella catarrhalis, usually colonizing the nasopharynx and spreading to the paranasal sinuses and middle ear cavity. ${ }^{4,5}$ Risk factors from previous reports include the use of a pacifier, attendance of a day care center, absence of breastfeeding, parental smoking, presence of siblings, crowding, poverty, and frequent viral upper respiratory infections. ${ }^{6}$ By definition, it is a middle ear inflammation causing acute symptoms of ear pain and fever associated with ear findings of tympanic membrane redness, bulging, cloudiness, and immobility. ${ }^{7}$

In the Philippines, there is no available national data systematically estimating the prevalence of acute otitis media. There are sporadic reports on the prevalence of ear diseases among schoolchildren in schools, unpublished and published. 8 This prevalence data is important in assessing the burden of this disease, assisting in prioritizing acute otitis media in planning health services, and evaluating available interventions to prevent its occurrence and/or progression to significant complications such as pneumococcal meningitis and disabilities like hearing impairment.

In this regard, this study aims to estimate the prevalence of clinically diagnosed acute otitis media among children 12 years and below recruited from clusters of households and schools around health centers, and to characterize these children with acute otitis media.

\section{Methods}

A cross-sectional survey employing a multi-stage cluster sampling of children in households and/or schools around a health center was performed. Eleven provinces and two cities in Metro Manila were selected at random at the first stage. In each province, one city or municipality was 
randomly selected. In the selected city/municipality, one health center and one school were identified randomly. Children from 0 to 12 years were recruited from around the health centers and the schools. The study was conducted from November 2010 to January 2011, with teams of two otolaryngologists working simultaneously in 10 sites while teams of three or more worked in three of the sites.

Sample size calculated based on a 95\% level of confidence to attain a margin of error of $\pm 2 \%$ in the estimate of the prevalence of AOM was 786, using an initial estimate of $9 \%$. This value was obtained from a Glaxo Smith Kline study among 19 kindergarten schools in Kaoshiung, Taiwan (http://www.gsk.com.ph/otitis.html). The study was approved by the research ethics committee from the university where the authors are affiliated. Coordination with local government officials, particularly the city health officers and school district superintendents, and practicing otolaryngologists in the identified study sites was performed to facilitate the conduct of the study. A group of 11 otolaryngologists certified by the Philippine Board of Otolaryngology-Head and Neck Surgery practicing for 2 years or more were recruited and divided into teams of two persons and assigned to two study sites. They were oriented on the study objectives and reviewed on the process of diagnosing acute otitis media and other ear disorders. A pilot activity was performed to have a dry run of the activities and to determine logistics and possible administrative problems that may arise in a study area.

All children from 0 to 12 years of age among households around the primary health center and schools, with signed informed consent by the parents or guardians, were recruited with the assistance of community health workers, who were assigned a number of households, and school teachers.

The situation in the study sites was that the schools were beside or within walking distance to the health centers where the investigators were based. The local otolaryngologists, with the help of the barangay health workers, informed the parents about the study, its objectives, benefits and harm to participants, through public lectures and written material provided by the investigators at least 1 week prior to the study. All of the households were given the information brochures and consent forms if they expressed willingness to participate. Response from the parents in the different sites was not consistent. Moreover, the city health officers and school superintendents insisted on the following conditions: (1) that the study be conducted in the secured premises of the health centers or schools mainly for the protection of the investigators and the study equipment; (2) that representatives from their offices be present during data collection even if there were guardians or parents since the study dealt with minors; (3) that the investigators must perform, at the very least, ear cleaning on the children when necessary. Ear cleaning of impacted cerumen and removal of epithelial debris is necessary to visualize the tympanic membrane and to perform tympanometry. The setting up of equipment such as a suction machine, irrigation apparatus, lamp, headlight, and tympanometer would be very difficult if the investigators went from house to house due to logistical and time constraints. According to the local officials, most homes did not have ample space and running water so it was not really feasible to set up the equipment. The teams stayed in the sites for a maximum of 3 days. Under certain circumstance, not all those who gave consent were accommodated. Though the target for each site was 100 to meet the sample size requirement, materials were prepared for 200 subjects. The investigators were allocated a budget to reproduce the study materials as needed on site since the instruction was to accommodate as many participants as possible during the investigation period. The local otolaryngologists and health workers gave an initial orientation and obtained consent from at least 100 subjects before the actual data collection; however, the health workers still had to fetch the parents or guardians with their children, one family at a time, in order to participate.

On the day of data collection, parents or guardians were given forms to fill out (which included demographic data) followed by an interview of the children together with the parents to confirm their answers. The children underwent height and weight metric measurements, otoscopic examination, ear cleaning if necessary, tympanometry, and hearing testing using the Hearcheck Navigator ${ }^{\mathrm{TM}}$ (Siemens). Findings were recorded in a case report form, encoded, and processed using the EPI-INFO v.6 program (CDC). Quality checks, cleaning, and validation of the database were performed prior to analysis. Data from EPI-INFO record files were then converted to STATA data sets.

Prevalences of AOM were calculated overall and by sex, age and area of survey. Ninety-five percent (95\%) confidence intervals for the prevalences were obtained. Tabulations of the outcome variables were generated using STATA Ver 10.1. Tests on differences of proportions were done using Chi-square tests. The level of significance was set at $\alpha=0.05$.

Due to logistical oversight, the documentation necessary to establish sampling weights was not performed. Consequently, the analysis of the data used methods that were designed for simple random sampling, instead of the multistage sampling design. The resulting confidence intervals would have been longer than those reflected in the results.

\section{Results}

The sample included 2,277 children from the 26 household and school clusters in the 13 areas (11 provinces and two cities in Metro Manila). The sample size per area ranged from 76 to 227, with an average of 175 and standard deviation of 49 children per area (Table 1). There were 1,081 
(47.5\%) males and 1,196 (52.5\%) females. Age ranged from 0 to 12 years old. Among children with available information on age, 219 (9.9\%) 0-2 years old, 588 (26.6\%) 3-6 years old (preschool children), and 1400 (63.4\%) 7-12 years old (schoolchildren). There were 70 children without age information, most of them abandoned or orphaned wards of health workers or community officials less than 10 years old, whose exact ages and dates of birth cannot be determined by the available guardian or informant.

Table 1. Distribution of Areas Surveyed

\begin{tabular}{lcc}
\hline \multicolumn{1}{c}{ AREA } & FREQUENCY & PERCENTAGE (\%) \\
\hline Bulacan & 104 & 4.6 \\
Laguna & 198 & 8.7 \\
Davao & 196 & 8.6 \\
Batangas & 204 & 8.9 \\
Cebu & 144 & 6.3 \\
Leyte & 227 & 10.0 \\
Iloilo & 201 & 8.8 \\
Camarines Sur & 241 & 10.6 \\
Misamis Oriental & 136 & 6.0 \\
Isabela & 187 & 8.2 \\
Marikina & 76 & 3.3 \\
Palawan & 209 & 9.2 \\
Manila & 154 & 6.8 \\
TOTAL & 2277 & 100 \\
\hline
\end{tabular}

There were 218 children with clinically diagnosed acute otitis media, with an overall prevalence rate of $9.6 \%$ (95\% CI: $8.4 \%-10.9 \%$ ) (Table 2). Mean prevalence was $9.5 \%$ ( $\mathrm{sd}=5.4 \%$ ) among the different areas (Table 3). There was great variability in the prevalence of AOM in the different areas $\left(\chi^{2}=81.74, \mathrm{p}<0.0001\right)$. The prevalences were as low as $0.0 \%$ to as high as $18.7 \%$. The biggest cluster of seven areas had prevalences that ranged from $10 \%$ to $15 \%$. This was followed by another cluster of three areas with lower prevalences from $5 \%$ to $8 \%$. The remaining areas were in the extremely low or high prevalences.

Table 2. Overall Prevalence of AOM by Type

\begin{tabular}{lcc}
\hline & No of cases & Prevalence $\%$ \\
\hline Unilateral & 96 & $4.2 \%$ \\
Bilateral & 122 & $5.4 \%$ \\
TOTAL & 218 & $9.6 \%$ \\
\hline
\end{tabular}

According to type of examination center, there were also significant differences in the prevalence of AOM (Table $\left.4, \chi^{2}=6.43, \mathrm{p}=0.0400\right)$. The prevalence of AOM was highest among the private schools with 5 of 34 students $(14.7 \%, 95 \%$ CI: $5.0 \%-31.1 \%)$. Schoolchildren examined at health centers had the next highest prevalence with $11.0 \%$ (95\% CI: $9.0 \%$ $13.2 \%)$. The lowest prevalence was among public school children $(8.0 \%$, 95\% CI: $6.5 \%$ - 9.7\%). There were 139 children whose examination centers were not determined. These were most likely children from public schools who were not seen or finished during school hours but were seen on the same day or following day in the nearby health center. Nevertheless, the main purpose of the study is to be able to survey these children whether they are surveyed in school or in the nearby health center.

Table 3. Prevalence of AOM according to Study Area

\begin{tabular}{lccccccc}
\hline & & \multicolumn{2}{c}{ Unilateral } & \multicolumn{2}{c}{ Bilateral } & \multicolumn{2}{c}{ Total } \\
\cline { 3 - 8 } AREA & $\mathbf{n}$ & $\begin{array}{c}\text { No of } \\
\text { cases }\end{array}$ & $\begin{array}{c}\text { Prev } \\
\text { \% }\end{array}$ & $\begin{array}{c}\text { No of } \\
\text { cases }\end{array}$ & $\begin{array}{c}\text { Prev } \\
\text { \% }\end{array}$ & $\begin{array}{c}\text { No of } \\
\text { cases }\end{array}$ & $\begin{array}{c}\text { Prev } \\
\text { \% }\end{array}$ \\
\hline Bulacan & 104 & 4 & 3.9 & 3 & 2.9 & 7 & 6.7 \\
Laguna & 198 & 3 & 1.5 & 8 & 4.0 & 11 & 5.6 \\
Davao & 196 & 0 & 0 & 0 & 0 & 0 & 0 \\
Batangas & 204 & 0 & 0 & 1 & 0.5 & 1 & 0.5 \\
Cebu & 144 & 7 & 4.9 & 14 & 9.7 & 21 & 14.6 \\
Leyte & 227 & 13 & 5.7 & 20 & 8.8 & 33 & 14.5 \\
Iloilo & 201 & 11 & 5.5 & 13 & 6.5 & 24 & 11.9 \\
Camarines & 241 & 15 & 6.2 & 30 & 12.5 & 45 & 18.7 \\
Sur & & & & & & & \\
Misamis & 136 & 14 & 10.3 & 0 & 0 & 14 & 10.3 \\
Oriental & & & & & & & \\
Isabela & 187 & 12 & 6.4 & 7 & 3.7 & 19 & 10.2 \\
Marikina & 76 & 5 & 6.6 & 5 & 6.6 & 10 & 13.2 \\
Palawan & 209 & 8 & 3.8 & 13 & 6.2 & 21 & 10.1 \\
Manila & 154 & 4 & 2.6 & 8 & 5.2 & 12 & 7.8 \\
TOTAL & 2277 & 96 & 4.2 & 122 & 5.4 & 218 & 9.6 \\
\hline
\end{tabular}

Table 4. Prevalence of AOM according to Place of Survey

\begin{tabular}{lccccccc}
\hline \multirow{2}{*}{ Place } & & \multicolumn{2}{c}{ AOM } & \multicolumn{3}{c}{ Unilateral AOM } & \multicolumn{2}{c}{ Bilateral AOM } \\
\cline { 3 - 8 } & $\mathbf{n}$ & $\begin{array}{c}\text { No of } \\
\text { cases }\end{array}$ & Prev \% & $\begin{array}{c}\text { No of } \\
\text { cases }\end{array}$ & Prev \% & $\begin{array}{c}\text { No of } \\
\text { cases }\end{array}$ & Prev \% \\
\hline Health Center & 894 & 98 & $11.0 \%$ & 41 & $4.6 \%$ & 57 & $6.4 \%$ \\
Public School & 1210 & 97 & $8.0 \%$ & 47 & $3.9 \%$ & 50 & $4.1 \%$ \\
Private School & 34 & 5 & $14.7 \%$ & 3 & $8.8 \%$ & 2 & $5.9 \%$ \\
TOTAL & $\mathbf{2 1 3 8}$ & $\mathbf{2 0 0}$ & $\mathbf{9 . 4 \%}$ & $\mathbf{9 1}$ & $\mathbf{4 . 3 \%}$ & $\mathbf{1 0 9}$ & $\mathbf{5 . 1 \%}$ \\
\hline
\end{tabular}

There is no gender predilection in the prevalence of AOM. Small difference in the prevalence between sexes (Table 5, $\chi^{2}=0.4129, \mathrm{p}=0.5210$ ). The prevalence among male children was $10.0 \%$ (95\% CI: $8.3 \%$ - $11.9 \%$ ) compared to $9.2 \%$ (95\% CI: $7.6 \%$ - 11.0\%) among females. AOM was more common in younger children. The prevalence among the 0 to 2 year old children was $14.6 \%$ (95\% CI: $10.2 \%-20.0 \%)$. This was significantly higher than the prevalence in children 3-6 years $(9.5 \%, 95 \%$ CI: $7.0 \%-9.9 \%)$ and schoolchildren $(8.4 \%$, $95 \%$ CI: $7.3 \%-12.2 \%)\left(\chi^{2}=8.8455, p=0.0120\right)$.

Table 5. Distribution of Children with AOM according to Gender

\begin{tabular}{lcccc}
\hline & \multicolumn{2}{c}{ Male $(\mathbf{n}=\mathbf{1 0 7 7})$} & \multicolumn{2}{c}{ Female $(\mathbf{n}=\mathbf{1 2 0 0})$} \\
\cline { 2 - 5 } & No of cases & Prev $\%$ & No of cases & Prev $\%$ \\
\hline Unilateral & 42 & $3.9 \%$ & 54 & $4.5 \%$ \\
Bilateral & 66 & $6.1 \%$ & 56 & $4.7 \%$ \\
TOTAL & $\mathbf{1 0 8}$ & $\mathbf{1 0 . 0} \%$ & $\mathbf{1 1 0}$ & $\mathbf{9 . 2} \%$ \\
\hline
\end{tabular}

Of the 218 children with AOM, bilateral type was more common than unilateral AOM. One hundred twenty-two children $(56.0 \%)$ had AOM in both ears while the other 96 children $(44.0 \%)$ had unilateral AOM (Table 2). These numbers converted to prevalence of unilateral AOM of $4.2 \%$ and bilateral AOM of $5.4 \%$ in children 0 to 12 years. Across areas, the prevalence of bilateral $\mathrm{AOM}$ ranged for $0 \%$ to 
$12.5 \%$ (Table 3). There were significant differences in these prevalences between areas $\left(\chi^{2}=66.89, \mathrm{p}<0.0001\right)$. One group of six areas had low prevalences (less than 5\%) while a similar number of areas had prevalences from 5 to $10 \%$. Prevalences of unilateral AOM between areas significantly differed $\left(\chi^{2}=42.65, p<0.0001\right)$. Six areas had prevalence of $5 \%$ or higher, while the remaining seven areas had less than $5 \%$. Two areas had $0 \%$ prevalence.

The prevalence of unilateral AOM was $4.6 \%$ and $3.9 \%$ in health centers and public school children, respectively, while the prevalence of bilateral AOM was $6.4 \%$ and $4.1 \%$, respectively (Table 4). The prevalence of unilateral AOM among male children was $3.9 \%$ and $4.5 \%$ among female children (Table 5). Bilateral AOM was present in $6.1 \%$ of the male and $4.7 \%$ of the female children.

Bilateral AOM was more common in the youngest age group (Table 6, $\chi^{2}=9.0606, \mathrm{p}=0.0110$ ). The prevalence of bilateral $\mathrm{AOM}$ in the $0-2$ year old children was $9.1 \%$, higher than the $5.4 \%$ and $4.4 \%$ prevalence in 3-6 year old and 7-12 year old age categories. Differences in prevalence of unilateral AOM between age groups were smaller and not significant $\left(\chi^{2}=1.0528, \mathrm{p}=0.5910\right)$. The prevalence ranged from $4.0 \%$ among the schoolchildren to $4.1 \%$ among the 3-6 year old children to $5.5 \%$ among the $0-2$ year old children.

Table 6. Distribution of Children with Clinically Diagnosed AOM according to Age

\begin{tabular}{lccccccc}
\hline \multirow{2}{*}{$\begin{array}{c}\text { Age (in } \\
\text { years) }\end{array}$} & $\mathbf{n}$ & \multicolumn{3}{c}{ Diagnosed with AOM } & \multicolumn{2}{c}{ Unilateral AOM } & \multicolumn{2}{c}{ Bilateral AOM } \\
\cline { 3 - 8 } & & $\begin{array}{c}\text { No of } \\
\text { cases }\end{array}$ & Prev \% & $\begin{array}{c}\text { No of } \\
\text { cases }\end{array}$ & $\begin{array}{c}\text { Prev } \\
\%\end{array}$ & $\begin{array}{c}\text { No of } \\
\text { cases }\end{array}$ & $\begin{array}{c}\text { Prev } \\
\mathbf{\%}\end{array}$ \\
\hline $0-2$ & 219 & 32 & $14.6 \%$ & 12 & $5.5 \%$ & 20 & $9.1 \%$ \\
$3-6$ & 588 & 56 & $9.5 \%$ & 24 & $4.1 \%$ & 32 & $5.4 \%$ \\
$7-12$ & 1400 & 117 & $8.4 \%$ & 56 & $4.0 \%$ & 61 & $4.4 \%$ \\
TOTAL & $\mathbf{2 2 0 7}$ & $\mathbf{2 0 5}$ & $\mathbf{9 . 3} \%$ & $\mathbf{9 2}$ & $\mathbf{4 . 2} \%$ & $\mathbf{1 1 3}$ & $\mathbf{5 . 1 \%}$ \\
\hline
\end{tabular}

The frequency of the occurrence of unilateral AOM in the left ear seemed to be higher than in the right ear (Table $7)$. There were 58 cases of unilateral AOM in the left ear $(2.5 \%)$ compared to $38(1.7 \%)$ in the right ear (one-sided binomial test $\mathrm{p}=0.0260$ ).

Table 7. Prevalence of Ear Diagnoses among Children Surveyed

\begin{tabular}{|c|c|c|c|c|}
\hline \multirow[t]{2}{*}{ DIAGNOSIS } & \multicolumn{2}{|c|}{$\begin{array}{c}\text { No. of unilateral } \\
\text { cases }\end{array}$} & \multirow{2}{*}{$\begin{array}{c}\text { No of } \\
\text { bilateral } \\
\text { cases }\end{array}$} & \multirow{2}{*}{$\begin{array}{c}\text { Total no of } \\
\text { cases } \\
\text { (prevalence \%) }\end{array}$} \\
\hline & Left & Right & & \\
\hline $\mathrm{AOM}$ & 58 & 38 & 122 & $218(9.6 \%)$ \\
\hline OME & 24 & 30 & 30 & $84(3.7 \%)$ \\
\hline CSOM & 27 & 25 & 19 & $71(3.1 \%)$ \\
\hline AOM Complications & 11 & 12 & 13 & $36(1.6 \%)$ \\
\hline Others & 156 & 147 & 398 & $701(30.9 \%)$ \\
\hline Total & 276 & 252 & 582 & $1100(48.7 \%)$ \\
\hline
\end{tabular}

AOM = Acute otitis media; $O M E=$ Otitis media with effusion; $C S O M=$ Chronic suppurative otitis media

Other common ear diseases diagnosed during the survey showed $84(3.7 \%)$ children with otitis media with effusion, $71(3.1 \%)$ with chronic suppurative otitis media, and $36(1.6 \%)$ with complications of otitis media (Table 7 ). The frequency of these conditions did not differ in left or right ear. This was unlike in AOM where more unilateral infections in the left ear were seen than in the right ear.

\section{Discussion}

The overall prevalence of acute otitis media in this Philippine survey is $9.6 \%$, varying among the different areas surveyed. A study in Taiwan reported a prevalence of $7.46 \%$ to $13.2 \%$, depending on age and seasonality. The overall prevalence was $20 \%$, which is higher compared to our estimate. $^{10}$ If our estimate of $9.6 \%$ is true, then by extrapolation there are around 2,721,676 children having acute otitis media (out of 28,427,779 for the 0-14 age group, based on Philippine Health Statistics in 2005). It also appears from this survey that the prevalence is highest among the 0-2 year old children. Differences in prevalence according to place of examination were also noted, where private school children had higher prevalence, followed by those at health centers. These differences by place of examination could be attributed to selection bias. Participation among schoolchildren in the private school might have been affected by the presence of ear problems where those children without could have had less interest in participating. In health centers, a higher prevalence of AOM could have been expected since they are perceived as treatment centers. The lowest prevalence was among public school children at $8.0 \%$. This is still a big number and would necessitate employing a mass-based approach in introducing preventive strategies. The current strategy is early treatment with antibiotics, but there are still significant recurrences and antibiotic resistance and non-responses encountered, in addition to compliance issues, with progression to complicated acute otitis media. ${ }^{11,12}$ This underlies the importance of vaccines in preventing pneumococcal and Heamophilus acute otitis media, considered the more common isolates in AOM-confirmed cases, even though viral otitis media is still prevalent. ${ }^{4,13}$ At present, vaccines are available in the country but have not yet been introduced in the national immunization program, considering the cost of distributing vaccines to a significant number of the population.

The estimate is based on a cross-sectional survey of children at one point in time, and this may be an underestimation since case finding was confined to those who were able to submit themselves for examination at the time of the study. Continuous case finding in local health centers and schools may be important to validate this estimate. Logistics and resources are important considerations in performing house-to-house case finding of children with acute otitis media, especially in the community setting.

The diagnosis of AOM has been debated in several studies, but a study by Rosenfeld et al. has provided 
sensitivity and specificity of clinical symptoms and findings of the ear, and would lean on ear pain, ear rubbing, fever, and tympanic membrane findings of redness, bulging, cloudiness, and impaired mobility as predictive for acute otitis media, in addition to tympanometric findings. ${ }^{14}$ In this study, we used these parameters as these are the more prevalent and the current standard method of diagnosing AOM by most clinicians in the Philippines, including general practitioners, pediatricians, and otolaryngologists. Tympanocentesis is not a usual and routine clinical practice in the country, as this is an invasive procedure and would require a controlled set-up that most community health centers and even clinics and hospitals may not have. Tympanometry, in addition to otoscopic findings may be helpful in diagnosing AOM. A study done by Saeed and colleagues suggests a sensitivity and positive predictive value of a type B tympanogram to be $97 \%$ and $87 \%$, respectively. ${ }^{15}$

An approximately $10 \%$ overall prevalence of acute otitis media in the Philippines has been shown, with variable prevalence among provinces, signifying that it is an important public health problem, comparable to acute respiratory infections which have the same etiologic agents such as pneumonia. ${ }^{16}$ Strategies like vaccination and early treatment with antibiotics may be employed to reduce the burden of disease.

The resulting prevalences in this study have been derived using analysis for a simple random sampling design. It is known from statistical theory that this analysis, when applied to samples obtained by multi-stage sampling procedures, underestimates standard errors especially when there are cluster differences in the prevalences. ${ }^{17}$ It can also produce bias in the point estimates since the proper weighting of units has not been incorporated in the estimation procedures. Our methods would have produced unbiased point estimates if there was no heterogeneity in the prevalences across clusters (areas around health centers or schools) and no selection biases introduced in the implementation of the sampling procedures. Given our results of analysis, the real picture could only be uncovered if we had sufficient information about the characteristics at the level of the clusters and the occurrence of selection biases. In view of the fact that this information is not available, the results should be interpreted with caution. In the following discussion of our results, we presumed that there is no heterogeneity of the prevalences among clusters and connect them to what is known in the literature. We tried to identify sources of bias and discuss their implications. We recognize the underestimation of the widths of the confidence intervals and possible deflation of the p-values in tests of hypothesis (i.e. leading to more statistically significant results) and thus avoid any controversial debate arising from discrepancies with existing literature. This is a major limitation of the study.

\section{Conclusion}

The overall prevalence of clinically diagnosed acute otitis media in the Philippines is $9.6 \%$, with a variable areaspecific prevalence. There is no gender predilection, with the $0-2$ year old age group having the most prevalent cases of AOM in the sample.

Future attempts to conduct prevalence studies on AOM in the Philippines should be carefully planned. The involvement of an experienced statistician at the earliest possible phase, that is, at the planning stage, should be considered mandatory in order to avoid the problems related to the sampling design, sampling procedures, and data analysis. The presence of a data coordinator or manager to ensure the proper comprehensive documentation of the implementation of these steps to allow for assessment of the validity and reliability of the results would be beneficial.

\section{Acknowledgments}

We wish to thank Marilla Lucero MD for her assistance in the development of the protocol.

\section{References}

1. Rovers MM. The burden of otitis media. Vaccine. 2008; 26 Suppl 7:G2-4.

2. Greenberg D, Bilenko N, Liss Z, Shagan T, Zamir O, Dagan R. The burden of acute otitis media on the patient and family. Eur J Pediatr. 2003; 162(9):576-81.

3. Dubé E, De Wals P, Gilca V, et al. Burden of acute otitis media on Canadian families. Can Fam Physician. 2011; 57(1):60-5.

4. Jansen AG, Hak E, Veenhoven RH, Damoiseaux RAMJ, Schilder AG, Sanders EA. Pneumoccocal conjugate vaccines for preventing otitis media. Cochrane Database Syst Rev. 2009 Apr 15;(2):CD001480..

5. Grevers G. First International Roundtable Meeting Group. Challenges in reducing the burden of otitis media disease: an ENT perspective on improving management and prospects for prevention. Int J Pediatr Otorhinolaryngol. 2010; 74(6):572-7.

6. Lubianca Neto JF, Hemb L, Silva DB. Systematic literature review of modifiable risk factors for recurrent acute otitis media in childhood. J Pediatr (Rio J). 2006; 82(2):87-96.

7. American Academy of Pediatrics Subcommittee on Acute Otitis Media Diagnosis and management of acute otitis media. Pediatrics. 2004; 113(5):1451-65.

8. Mahadevan M, Navarro-Locsin G, Tan HK, et al. A review of the burden of disease due to otitis media in the Asia-Pacific. Int J Pediatr Otorhinolaryngol. 2012; 76(5):623-35.

9. Lucero MG, et al. The prevalence of AOM in the Asia-Pacific: A systematic review. 2005. Unpublished.

10. Ting PJ, Lin $\mathrm{CH}$, Huang FL, et al. Epidemiology of acute otitis media among young children: a multiple database study in Taiwan. J Microbiol Immunol Infect. 2012; 45(6):453-8.

11. Dagan R. Appropriate treatment of acute otitis media in the era of antibiotic resistance. Paediatr Drugs. 2010; 12 Suppl 1:3-9.

12. Vergison A, Dagan R, Arguedas A, et al. Otitis media and its consequences: beyond the earache. Lancet Infect Dis. 2010; 10(3):195-203.

13. Boonacker CW, Broos PH, Sanders EA, Schilder AG, Rovers MM. Costeffectiveness of pneumococcal conjugate vaccination against acute otitis media in children: a review. Pharmaeconomics. 2011; 29(3):199-211.

14. Rosenfeld RM. Diagnostic certainty for acute otitis media. Int J Pediatr Otorhinolaryngol. 2002; 64(2):89-95.

15. Saeed K, Coglianese CL, McCormick DP, Chonmaitree T. Otoscopic and tympanometric findings in acute otitis media yielding dry tap at tympanocentesis. Pediatr Infect Dis J. 2004; 23(11):1030-4.

16. Weil-Olivier C, van der Linden M, de Schutter I, Dagan R, Mantovani L. Prevention of pneumococcal diseases in the post-seven valent vaccine era: a European perspective. BMC Infect Dis. 2012; 12:207.

17. Cochran W. Sampling Techniques. New York : John Wiley and Sons; 1977. pp 233-243. 